\title{
Khartoum 2030: towards the healthy city
}

\author{
A. M. Ahmad \\ Department of Architecture, Faculty of Engineering and Architecture, \\ University of Khartoum, Sudan
}

\begin{abstract}
At Independence, in 1956, the Sudanese capital, Khartoum, ranked among the healthiest and most attractive Arab capitals. Today, five decades later, it has dropped to settle among the world's bottom capitals in the quality of its physical and socio-cultural environments. This is manifest in the persistent cropping up of squatter settlements around it, the inadequacy of surface water drainage, the poverty of sewage disposal systems, the depletion of greenery, the shortage and unacceptable quality of drinking water and the traffic chaos and all that emanates from it.

In a retarded country almost permanently in dictatorial grips so little reliable data exists that we can write about scientific issues only in general qualitative terms. Yet, I shall attempt to describe the great potential of the city, highlight the main physical environmental threats, discuss the recent positive developments, then argue that Khartoum has the potential to mature into a model Healthy City by, say, 2030.
\end{abstract}

Keywords: healthy city, Khartoum, environmental hazards, post-oil development.

\section{Introduction}

A recent 'quality of living' report has rated Khartoum fifth from the bottom - the $211^{\text {th }}$ of 215 cities surveyed. The survey conducted by Mercer Human Resources Consulting in 2006 analysed '39 quality of life criteria for each city including political, economic and social factors, personal safety and health, education, transport and other public services' and ranked the cities accordingly [1].

Lower than Khartoum in ranking came only Pointe Noire (Congo), Baghdad (Iraq), Bangui (Central African Republic) and finally Brazzaville (Congo), the world's worst city to live in by Mercer's criteria. One sees at a glance that these cities, unlike Khartoum, have been or are being devastated by long civil wars - 
which further underlines the backward state of Khartoum. Of the bottom twenty cities seventeen were African. Incidentally, the top cities were Zurich, Geneva, Vancouver and Vienna.

Even allowing some room for contesting the criteria or the procedure for ranking, the fact remains that Khartoum has a pretty dismal environment to offer its residents.

These pages will look only into the environmental health aspects of the city in light of the available information and will argue that there is still room for hope under the newly emergent conditions and that it will be possible to upgrade it to the status of an ideal Healthy City in the span of some 25 years.

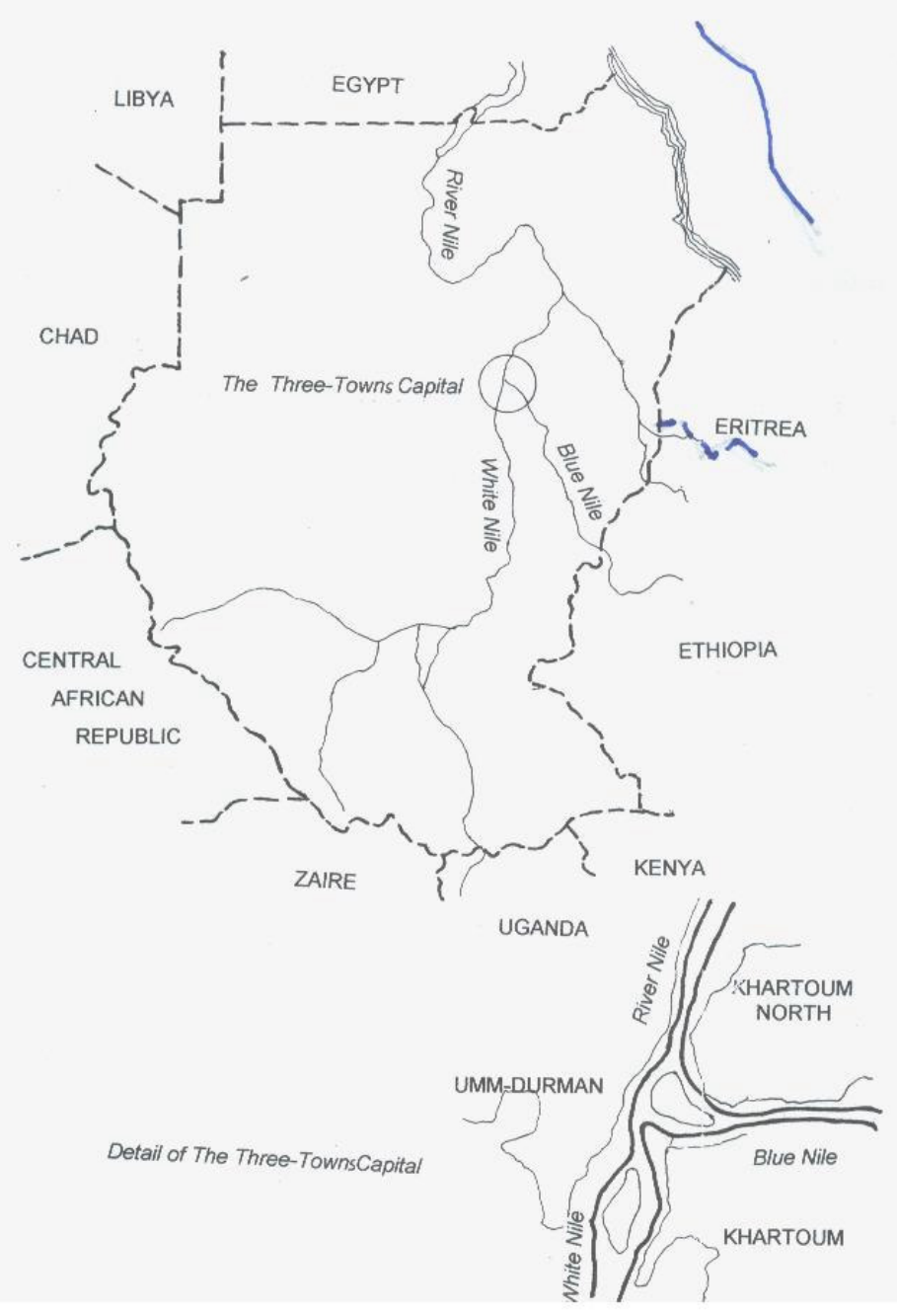

Figure 1: The Sudan and the national capital, Khartoum. 


\section{Background}

Khartoum enjoys a distinctive location at the heart of a huge country. At its own heart the Blue Nile advancing from the south east and the White Nile from the south merge and flow jointly northwards dividing Greater Khartoum into three discrete sectors: Khartoum, Umm-Durman, and Khartoum North (fig 1). The terrain is mostly flat except in Umm-Durman where it is fairly rugged and the soil is clayey and fertile in Khartoum and Khartoum North and sandy or rocky in Umm-Durman. The city (lat $1536^{\prime} \mathrm{N}$ ) lies in a semi-desert zone with a hot dry season coming in two installments extending over about seven months, a twomonth rainy season and a brief cool dry season lasting about three months; but the approaching desert, not yet effectively confronted, is gradually transforming the region into a typical hot dry zone. Mean air temperatures range from 27.3 to $41.9^{\circ} \mathrm{C}$ in May and from 15.6 to $30.7^{\circ} \mathrm{C}$ in January. Total annual rainfall amounts to $121 \mathrm{~mm}$ spread mainly over July, August and September. About twelve dust storms blow annually [2]. Today, the city is gradually being engulfed and desiccated by the critical buffer front of the advancing desert aided by harmful human activities and irresponsible government policies.

The city suffers from sprawl; it has a very low density, its buildings being predominantly single storey and with vast open spaces within its boundary. The population of Khartoum (the name now referring to the whole city) is unknown the last census was conducted in 1993 and since then civil wars and natural disasters have caused considerable population swings with the displaced people heading mostly towards the national capital. The current official population estimate is seven million, almost a fifth of the total population of the country.

\section{Environmental health risks}

Let us review the major environmental health risks affecting Khartoum.

\subsection{Surface water drainage}

One of the disadvantages of the flat terrain is poor natural drainage. In Khartoum this is coupled with old constructed drains that, having outlived their usefulness, promptly fill up until natural evaporation empties them.

During the rainy season and with heavy rainfall on the Ethiopian highlands Khartoum urban areas are threatened by water in three forms: rainfall, river overflows every about 7 years and floodwater from outside its boundary. This has to be considered simultaneously with substandard road construction, untreated open spaces, inadequate garbage disposal and vulnerability to river flooding. A single heavy rain cripples the city for several days: vehicles are stranded, roads damaged, employees cannot be questioned about their absence when their homes are at risk of collapsing if immediate measures to get rid of the water are not taken (fig 2).

The incidence of malaria in the Sudan has been one of the highest in the Arab region but again no reliable data exist because of the selective sampling and 
because the whole southern region has been inaccessible for three decades. The specialized centre for malaria in Abu Usher south of Khartoum has long been closed.

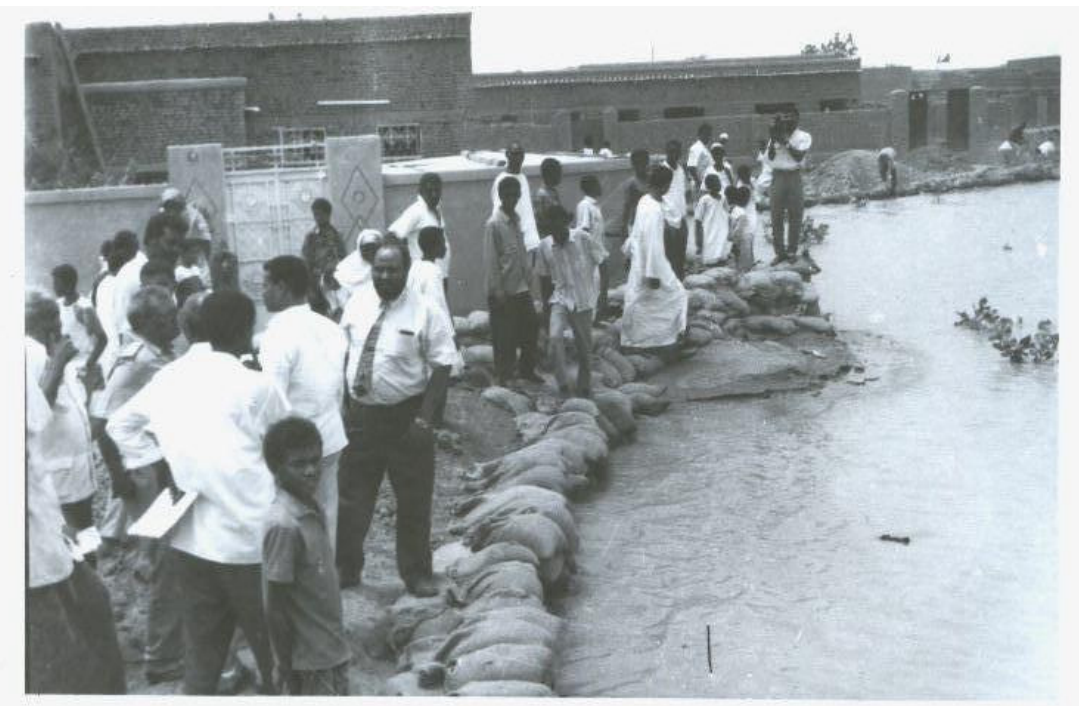

Figure 2: $\quad$ River overflows in suburban Khartoum.

\subsection{Squatter settlements}

Another disadvantage of the flat terrain is the relative ease with which illegal settlements materialise and slowly entangle the city. The successive natural and man-made disasters have resulted in millions of displaced people and refugees to neighbouring countries. Government estimates give illegal settlers as fully $50 \%$ of the total population of Khartoum i.e. about 3.5 million souls.

While it is comforting that those victims ultimately find refuge in the city, it is a tangible reality that their effect on the urban environment is detrimental. The majority of these communities are illiterate and some can hardly communicate in Arabic. They live in substandard shelter lacking safe drinking water, toilet facilities, employment opportunities and basic health, education and entertainment facilities and experience difficulties in being accepted by the original population. They live in continual contact with their domestic animals. Admittedly, they produce little waste and are competent in recycling and finding new uses for other people's waste. However, they cut down trees for fuel, fodder and home construction; their goats feed freely on any handy greenery. Some of them are engaged in crime: theft, liquor brewing, prostitution and practices approaching witchcraft. The incidence of AIDS/HIV among them is known to be higher than the city's average although no official figures are ever divulged. 


\subsection{Sewage disposal}

The sewage network covers no more than $7 \%$ of the city. It is old dating back to the1950s with frequent nasty overflows sometimes invading the drinking water network. Part of the First and Second Class residential areas (as the colonial classification has them) are served alternatively by septic tanks and soak-away wells (about $8 \%$ ). But the majority of the houses, about $85 \%$, are served by pit latrines. Part of the squatter areas totally lacks this service [3].

Sinking wells and pit latrines is expensive especially in Umm-Durman where the soil is rocky and the first aquifer lies at depths of 20-40 metres. They also work towards polluting the soil and the ground water. In old Umm-Durman with its traditional organic layouts and narrow twisting lanes, introducing a sewage network is an enormously demanding task, technically and economically. Disposal of treated sewage used to be in the green belt, a stretch 10 kilometres long 3.5 kilometres wide south of Khartoum. This was grown in 1961, remained healthy for over a decade and then dried and devastated through official negligence and the activities of squatters already mentioned. By the late 1970s the belt had disappeared. Other green belts have been proposed in subsequent master plans but never implemented. Sewage disposal remains one of the major ailments of the city.

\subsection{Traffic}

Traffic problems are on the rise. They emanate less from the presence of too many vehicles than from the absence of effective planning. The number of vehicles rose progressively from 148,000 in 1984 to 380,000 in 2003 to 400,000 in 2004 to 460,000 in 2005. At present this number is increasing at the rate of $120-150$ a day. This constitutes about $80 \%$ of the total vehicles in the country and $90 \%$ of these are private cars. In 2004 the number of deaths due to traffic accidents was 1306; in 2005 it was 1403 [4].

There are no statistics for the suburban traffic that enters the city in the early morning and leaves by the late afternoon. This traffic is a main 'ruralising' influence on the city due to the chaos it creates; sadly, it also has a known corrupting influence on some of the police. No segregation of vehicles by size has been planned in the streets and huge trucks coming from Port Sudan on the Red Sea keep entering the city all day long and mixing with its the normal traffic.

Traffic planning has not kept up with this increase. Private car ownership is rising; public transport is less than adequate. No attempt to plan parking in the city centre has yet been made.

Only in the last few years have official eyes turned to this field - two bridges have been constructed one across the Blue Nile and one across the White Nile; two more are under construction across the Blue Nile raising the number of bridges serving the city to eight.

Still on the drawing boards are plans for inner, middle and outer ring roads circling the three towns to reduce congestion. 


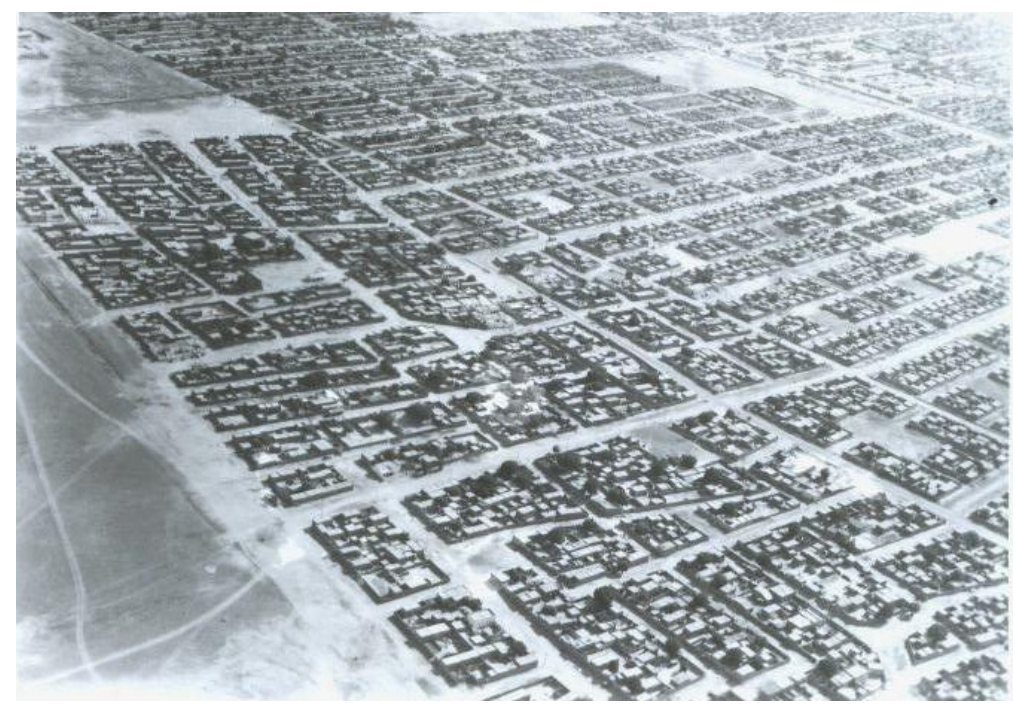

Figure 3: Low-density housing projects increase the city's sprawl and reduce its efficiency.

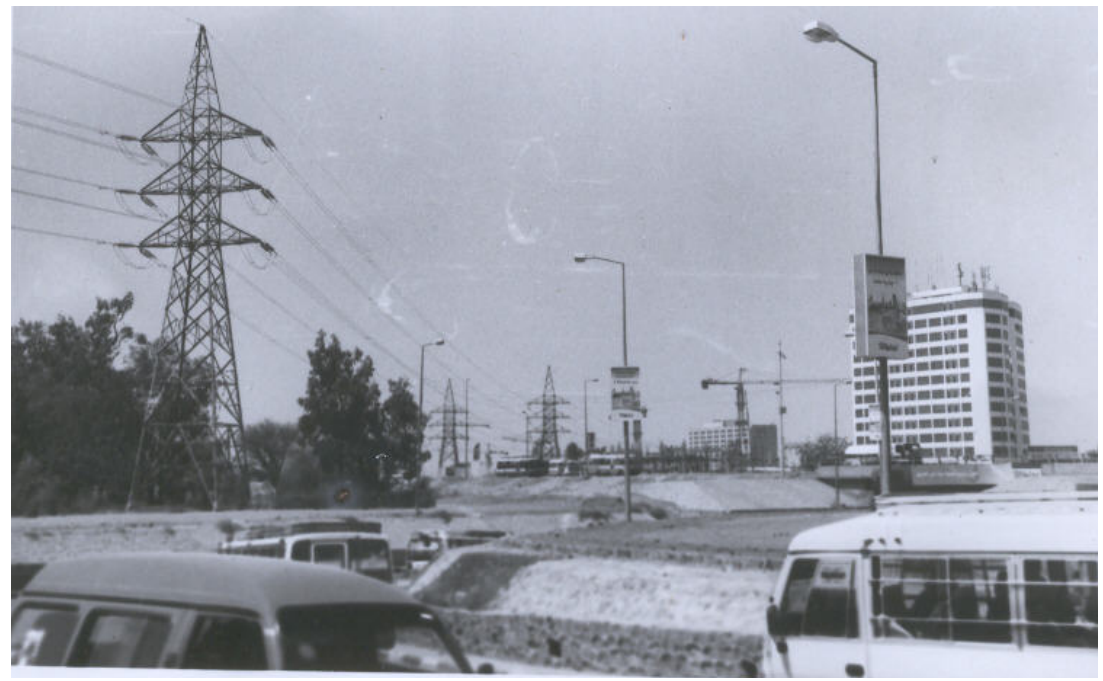

Figure 4: High voltage electricity lines crossing residential areas spread a new hazard: electro magnetic fields (EMFs). 


\subsection{Electromagnetic fields (EMFs)}

The host of urban hazards constantly within our visual, auditory and olfactory fields has been joined lately by more subtle newcomers: electromagnetic fields (EMFs).

These fields are known to impair human health through their emission of waves penetrating the body, the EM energy absorbed is then converted to heat within its cells causing brain cancer and leukemia, with the youth and children being its most vulnerable group (fig 4).

Khartoum is being invaded by two sources of EM fields: high tension electricity lines and mobile base stations. No attempts have been made to maintain recommended safe distances, given as $150 \mathrm{~m}$, from residential areas and some officials keep shamelessly dismissing the EM hazard as grossly exaggerated.

\section{Recent positive developments}

A bright side has recently emerged due to three potentially positive, inter-related developments in the country forcing developmental, economic goals finally to take priority over political ones.

First, oil exports started in July 1999. Since then the exported quantity has risen to 450,000 barrels a day, an official figure disputed by opposition leaders who regard it as deliberately played down and is nearer 800,000 barrels a day [5]. The price has mounted from $\$ 25$ then to over $\$ 60$ a barrel. Total oil reserves are estimated by the government at 5 billion barrels. Eyes worldwide started as a consequence to get set on the Sudan.

Secondly, a peace agreement was concluded in 2005 which ended a 21-year civil war in the south. Two of its consequences are of direct relevance to our subject. One is the saving of a daily $\$ 2$ million allegedly spent by the government in the war. The other is that the peace should trigger counter migration of southern displaced people from the national capital back to their abandoned home provinces; at least a million people are expected to quit Khartoum by early 2008, the time set for launching the fifth population census.

Thirdly, the country suddenly became a magnet for Arab, Western and Asian (mainly Chinese) investors and sizable projects are now in the making. Foreign investments have so far (in February 2007) reached \$6 billion [6]. The economy is currently one of the fastest growing in Africa - the International Monetary Fund (IMF) expects Sudan's GDP to grow by $13 \%$ in 2007 . And of these revenues the national capital will inevitably get the lion's share.

As I was finalising this text the government declared that all drugs for malaria will henceforth be given free as well as HIV/AIDS tests.

Two new industrial areas are being constructed at the fringes of the city and when part of the existing factories and workshops move out to them a relieving effect on the related traffic volume and flow and on air quality will be felt.

The Marawi Dam, presently under construction $350 \mathrm{~km}$ north of Khartoum is calculated to produce $1259 \mathrm{MW}$ and drastically reduce the frequent power cuts suffered by the city. 


\section{Towards the healthy city}

Most of the ingredients for a 'healthy city' exist in Khartoum. The time seems ripe to exploit them and the expected benefits are certain to outweigh the costs: a favourable physical setting, plentiful water resources, fertile soil, available capital, available professional expertise and the fact that most of the foregoing environmental problems are still at an early manageable stage.

The achievement of a 'healthy city' by 2030 is by no means a wild dream. Yet turning Khartoum into a sustainable healthy city requires more than solving the problems within its boundaries. It requires immediate implementation of the decentralisation policy officially adopted in 1971. That should create a dynamic series of provincial capitals and an effective hierarchy of settlements over the country and thus help in reaching distant regions and stemming the migration tide to the national capital.

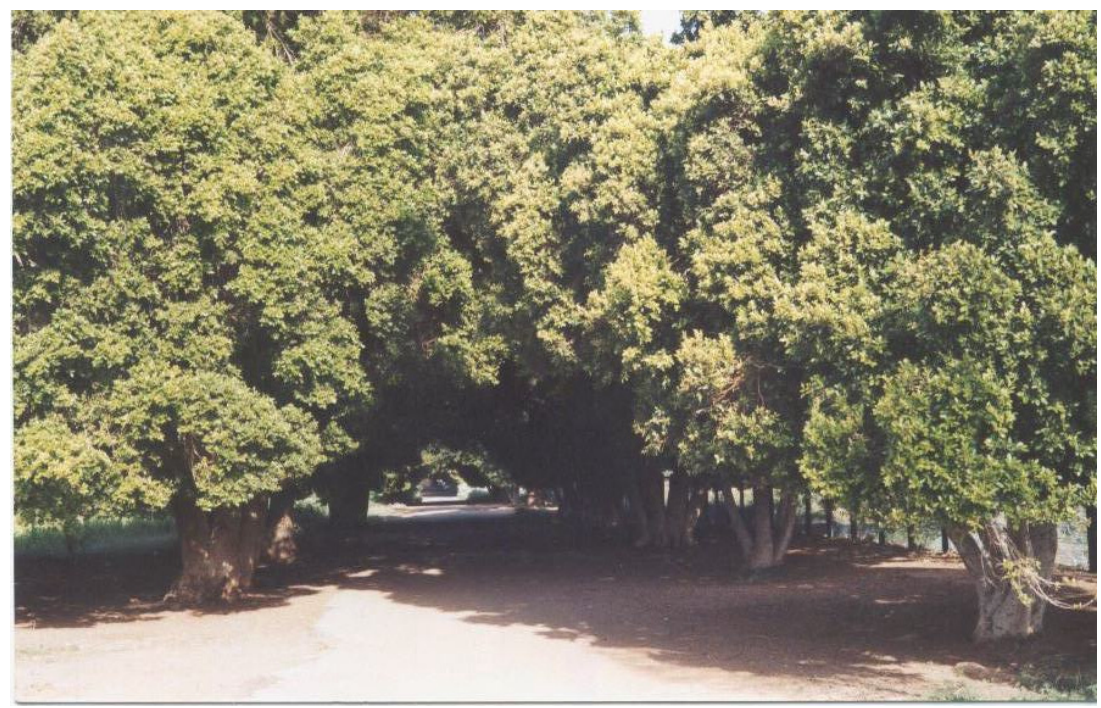

Figure 5: $\quad$ Some parts of Khartoum have retained their old dense greenery.

It also requires drastic measures against the city's own sprawl and for increasing the present low densities. This will improve the physical environment and reduce the crippling inefficiency of the city, reduce journeys to work and atmospheric pollution (fig 4).

It requires efforts to 'green' the city once again - 'green' not in the superficial sense of restoring and consolidating its visible greenery but in the deeper sense of making the city more ecologically responsive, stopping trespassing on agricultural land and natural parks by converting them to residential uses for quick cash, reclaiming some of the lost parks and open spaces, reducing the ecological footprint of the city by exploiting its fertile banks and abundant fresh water for food and fuel production, moving harmful elements such as brick kilns well outside the urban boundary and so on (fig 5). 
The coming of an oil culture if not expertly handled can be detrimental to the Sudanese society - not unlike the current 'Islamist' rule imposed on this multicultural, multiethnic society. The symptoms are already in the horizon: calling Khartoum the Dubai of East Africa, being obsessed with a stereotypical western 'image' to attract foreign investors and a readiness to ignore the failures of this stereotype and shun the centuries-old accumulated knowledge. In my view, taking the Arab Gulf or Saudi Arabia as a model is a step in the wrong direction. To the educated Sudanese 'Gulf' conjures up an image of 'false' and for authenticity we may need to study, for example, the Brazilian, Indian, Malaysian or Mexican experience in architecture and urban development.

It is imperative for a genuine quantum leap that the whole approach to handling the environment be utterly transparent and scientific. Environmental Impact Assessments, for example, have been undertaken only when pressure was applied by the press or by such bodies as the Sudanese Environment Conservation Society. Such assessments should become standard practice and a proper data base should urgently be built to facilitate them.

The project will need detailed feasibility studies, time schedules, cost analyses, etc, which are beyond the scope of this brief review and will require sustained multidisciplinary team work. But before this, what is needed for this project to materialise is political will.

\section{Acknowledgements}

This is a shortened version of an unpublished report. Part of the data has been collected by M. Sc. (Physical Planning) students: Dalal Suliman, El Amin Awad, Fadl el Mula Abdel Basit, Loai Khalafalla, Mai Abdel Raouf, Mohamed el Ghazali, Nahla Omer, Reem Mohamed Seif, Salwa Awad, Sawsan Badi, Shereen Mohamed. However, they are not responsible for any views or criticisms expressed in this paper.

\section{References}

[1] BBC News. World's Worst Cities. Microsoft Internet Explorer. 2006.

[2] Government of the Sudan. Ministry of Interior Affairs. Meteorological Department. Climatic Normals (1970-2000)

[3] Interviews with officials in the Khartoum Municipality (Arabic). As-Sudani Newspaper. Khartoum, January 18, 2007.

[4] An interview with Major Muhammad Abdel Mageed El Tayyib, Director General of Khartoum Traffic Administration (Arabic). Ash-Sharq Al-Awsat. London. June 27, 2006.

[5] Edward Leeno: The Government is hiding half the oil production. (Arabic). As-Sahafa. Khartoum January 24, 2007.

[6] Minister of Finance: Foreign investment reaches $\$ 6$ billion apart from petrol. (Arabic). Al-Ayyam Newspaper, Khartoum, February 21, 2007. 